\section{Change in FVC and survival in chronic fibrotic hypersensitivity pneumonitis}

\author{
ABSTRACT \\ The predictive value of the decline in FVC by \\ $\geq 10 \%$ on survival in patients with fibrotic \\ hypersensitivity pneumonitis is unknown. Of 112 \\ patients included, 66 (59\%) had surgical lung \\ biopsies. Patients with $\geq 10 \%$ decline in predicted \\ FVC after 6-12 months had a significantly \\ increased risk of all-cause mortality (median \\ survival 53 months, 95\% Cl 37 to 69vs 139 \\ months, $95 \% \mathrm{Cl} 66$ to 212 months, $\mathrm{p}=0.007)$. On \\ multivariate analysis remained associated with \\ increasing mortality: decline in FVC by $\geq 10 \%$ \\ (HR 4.13, 95\% Cl 1.96 to 8.70, p=0.005), lower \\ FVC\% (HR 1.03, 95\% Cl 1.01 to $1.05, p=0.003$ ) \\ and with decreasing mortality improvement with \\ antigen avoidance (HR 0.18, 95\% Cl 0.04 to 0.77 , \\ $p=0.021$ ).
}

\section{INTRODUCTION}

Hypersensitivity pneumonitis (HP) is a common interstitial lung disease resulting from inhalation of a large variety of antigens by susceptible individuals. The disease is best classified as acute and chronic. Chronic HP can be fibrotic or non-fibrotic. ${ }^{1}$ The presence and extent of fibrosis is a major determinant of survival, ${ }^{23}$ but median survival of patients with fibrotic HP is longer than those with idiopathic pulmonary fibrosis (IPF), except when usual interstitial pneumonia like pattern is found. ${ }^{45}$

Lower FVC percentage at initial evaluation is related to survival in chronic HP. $^{6}$ In IPF, a decline of $\geq 10 \%$ of the predicted value after 6-12 months of follow-up is associated with a higher risk of mortality. ${ }^{78}$ Thus far, no such studies have been reported on fibrotic HP.

The objective of the present study was to evaluate the predictive value of a decline in FVC by $\geq 10 \%$ on survival in patients with fibrotic HP.

\section{METHODS}

Patients were identified from a database of 2375 patients seen between 1996 and 31 March 2014, of which 322 (13.5\%) had a diagnosis of HP. Of these, 112 cases with fibrotic HP were included, characterised by high resolution tomography (HRCT) scans performed within 6 months of diagnosis showing reticular pattern, parenchymal distortion or honeycombing. Spirometric tests were conducted at initial evaluation and after 6 months $(n=15)$ or 12 months $(n=97)$.
In cases with tests conducted after 6 and 12 months, only the last tests were considered. The exclusion of cases with FVC at 6 months did not change the results. The percentage FVC was recalculated according to predicted values proposed for the Brazilian population. ${ }^{9}$

All patients fulfilled the diagnostic criteria used in our centre for HP. ${ }^{1}$ Of 112 patients, 39 (35\%) had a diagnosis by clinical and HRCT criteria, 7 (6\%) by transbronchial biopsy and 66 (59\%) by surgical lung biopsies. Bronchoalveolar lavage was obtained in only 23 cases, with lymphocytic alveolitis in 12 (52\%).

The decline in FVC was calculated by considering the difference between percentages of predicted values. Data were expressed as mean $\pm \mathrm{SD}$ and compared by t-tests, analysis of variance (ANOVA) and $\chi^{2}$. Patients with a decline of $\geq 10 \%$ in FVC were compared with the remaining cases by Kaplan-Meier curves. Clinical improvement was characterised by decrease in symptoms (dyspnoea and cough) in two consecutive visits after antigen removal or avoidance.

The effect of clinical and functional data on survival was evaluated by Cox analysis.

The software SPSS V.22.0 was used for statistical analysis. Values of $\mathrm{p}<0.05$ were considered significant. The follow-up extended to 31 March 2015. The mortality considered was that by all causes. Three cases were censored on the date of lung transplantation.

Table 1 Main clinical, physiological and HRCT characteristics in patients separated according to $<10 \%(n=77)$ and $\geq 10 \%$ predicted FVC $(n=35)$ after 6 -12-month period

\begin{tabular}{|c|c|c|c|}
\hline Finding & $\begin{array}{l}<10 \% \text { FVC } \\
(n=77)\end{array}$ & $\begin{array}{l}\geq 10 \% \text { FVC } \\
(n=35)\end{array}$ & $\mathrm{p}$ Value \\
\hline Age, years & $57.3 \pm 13.0$ & $61.1 \pm 13.7$ & 0.16 \\
\hline Female sex, n (\%) & $55(71.4)$ & $23(74.3)$ & 0.37 \\
\hline Weight loss, n (\%) & $26(33.8)$ & $9(25.7)$ & 0.88 \\
\hline Dyspnoea, n (\%) & $69(89.6)$ & $29(82.9)$ & 0.32 \\
\hline Fine crackles, $\mathrm{n}(\%)$ & $61(79.2)$ & $29(82.9)$ & 0.65 \\
\hline Clubbing, n (\%) & $10(13.0)$ & $11(31.4)$ & 0.55 \\
\hline Inspiratory squeaks, n (\%) & $11(14.3)$ & $4(11.4)$ & 0.68 \\
\hline FVC $\%$ predicted, mean \pm SD & $66.1 \pm 18.6$ & $72.6 \pm 17.9$ & 0.09 \\
\hline $\mathrm{FEV}_{1} / \mathrm{FVC}$ & $0.86 \pm 0.07$ & $0.86 \pm 0.08$ & 0.89 \\
\hline $\mathrm{SpO}_{2}$, rest, mean $\pm \mathrm{SD}(\mathrm{n}=103)$ & $93.9 \pm 4.2$ & $92.9 \pm 4.4$ & 0.28 \\
\hline Reticular pattern, n (\%) & $51(66)$ & $24(68)$ & 0.71 \\
\hline Ground-glass opacities, n (\%) & $41(53)$ & $22(62)$ & 0.34 \\
\hline Mosaic, n (\%) & $34(44)$ & $16(45)$ & 0.87 \\
\hline Honeycombing, n (\%) & $26(33)$ & $10(28)$ & 0.58 \\
\hline Centrilobular nodules, n (\%) & $17(22)$ & $6(17)$ & 0.54 \\
\hline Vertical distribution—diffuse/upper lobes/lower lobes, n & $21 / 22 / 33$ & $9 / 10 / 14$ & 0.99 \\
\hline Axial distribution-central, peripheral, both, $n$ & $9 / 23 / 44$ & $9 / 9 / 21$ & 0.62 \\
\hline
\end{tabular}

\section{RESULTS}

The general characteristics of the 112 patients separated by $\geq 10 \%$ or $<10 \%$ decline in $\%$ FVC are shown in table 1 . Potential relevant exposures were reported by 107 (95.5\%) patients: 33 to moulds, 21 to birds, 5 to feather pillows, 1 to paints, 1 to pyrethroid insecticide and 46 to two or re sources (38 to birds and moulds). In cases, the antigen was not identified. General, functional and HRCT findings are shown in table 1 . The most common histological patterns found in surgical lung biopsy fibrosis $(40.9 \%)$, and usual interstitial pneumonia (UIP)-like pattern (9.0\%).

The mean time of follow-up was 4.6 years. Median survival was 95 months (95\% CI 53 to 137). At the end of follow-up, 43 patients had died.

Antigen avoidance was reported by 61 (54.4\%) patients, 45 patients remained exposed and in 6 patients the avoidance was uncertain. There was no difference in FVC decline between these three groups (ANOVA, $\mathrm{p}=0.12$ ). Of 61 patients who reported antigen avoidance, 25 reported sustained clinical improvement (41\%). The mean FVC remained stable in this group $(-0.034 \pm 0.361 \mathrm{~L})$ compared with the remaining cases in whom FVC declined $\quad(-0.178 \pm 0.283, \mathrm{p}=0.046)$. Median survival was greater in patients who achieved sustained clinical improvement after avoiding exposure (figure 1A). 

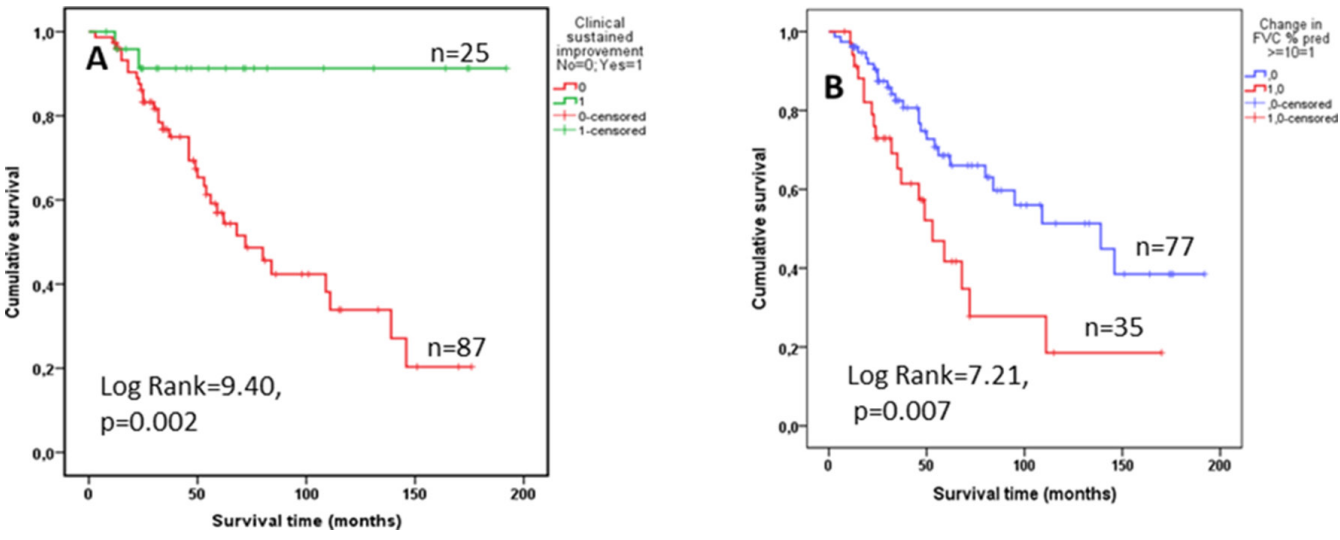

Figure 1 (A) Survival time estimate of chronic hypersensitivity pneumonitis cohort based on the presence of clinical sustained improvement after antigen avoidance $(n=25)$ or not $(n=87)$. (B). Survival time estimate of chronic hypersensitivity pneumonitis cohort based on decrease $<10 \%(n=77)$ and $\geq 10 \%$ predicted FVC $(n=35)$ after $6-12$-month period of follow-up.

Patients with a $\geq 10 \%$ decline in $\% F V C$ after 6-12 months had a significantly increased risk of all-cause mortality compared with those with $<10 \%$ decline in \%FVC (median survival 53 months, 95\% CI 37 to 69 vs 139 months, 95\% CI 66 to 112 months, $\mathrm{p}=0.007$ ) (figure $1 \mathrm{~B}$ ).

On univariate analysis the following variables were associated with increasing mortality: longitudinal decline in FVC by $\geq 10 \%$ (HR 2.22, 95\% CI 1.22 to $4.04, \mathrm{p}=0.009)$ and male sex (HR 2.10, $95 \%$ CI 1.15 to $3.82, \mathrm{p}=0.013)$, lower baseline \%FVC (HR 1.01, 95\% CI 1.00 to $1.03, p=0.046)$ and lower resting $\mathrm{SpO}_{2}$ (HR 1.08, 95\% CI 1.01 to 1.14 , $\mathrm{p}=0.023)$. Clinical improvement after antigen avoidance was associated with decreasing mortality (HR 0.14, 95\% CI 0.03 to $0.60, p=0.008)$. On multivariate analysis, a decline in FVC by $\geq 10 \%$ (HR $4.13,95 \%$ CI 1.96 to $8.70, p=0.005)$ as well lower baseline FVC\% (HR 1.03, 95\% CI 1.01 to $1.05, \mathrm{p}=0.003$ ) was associated with increased mortality and clinical improvement with antigen avoidance (HR $0.18,95 \%$ CI 0.04 to $0.77, p=0.021$ ) were associated with reduced mortality. Of the total number of patients, 107 were treated, 66 with corticosteroids and 41 with corticosteroids and immunosuppressants. The effect of treatment on survival was uncertain.

\section{DISCUSSION}

In the present study, an FVC percentage decline of $\geq 10 \%$ predicted in the first 6-12 months after diagnosis was associated with increased all-cause mortality in patients with fibrotic HP. The present study has several limitations. Diffusion of carbon monoxide (DLCO) decline was not measured. Increase in DLCO in chronic HP can occur in response to treatment with no significant changes in
FVC. ${ }^{10}$ Several patients claimed avoiding antigenic exposure without improvement. In Brazil, moulds associated with poor housing conditions are a common cause of HP and it is difficult to ascertain avoidance. Irreversible fibrosis could also be present. Severity of traction bronchiectasis is a greater predictor of mortality in chronic HP compared with baseline FVC, ${ }^{6}$ but in our study this variable was not evaluated. The primary outcome was all-cause mortality rather than respiratory causes, but this is a well-accepted outcome.

In summary, similar to IPF, a decline of $\geq 10 \%$ after in FVC after 6-12-month period is associated with a reduced survival in chronic HP, irrespective of initial FVC percentage. The present data need to be validated in prospective studies.

\section{Andrea Gimenez, Karin Storrer, Lilian Kuranishi, Maria Raquel Soares, Rimarcs Gomes Ferreira, Carlos A C Pereira}

Interstitial Lung Diseases Program, Federal University of São Paulo, São Paulo, Brazil

Correspondence to Dr Andrea Gimenez, Interstitial Lung Diseases Program, Federal University of São Paulo, R. Sena Madureira, 1500 - Vila Clementino, São Paulo 04023-062, Brazil; andrea.gimenez@bol.com.br

Contributors MRS contributed to the planning of the work. LK and KS contributed to conduct of the work.

Competing interests None declared.

Ethics approval Ethics committee in research from the Federal University of São Paulo.

Provenance and peer review Not commissioned; externally peer reviewed.

Author note Andrea gimenez acted in data collection, data analysis, bibliographical survey and wrote this paper. Carlos AC Pereira Advisor of doctoral thesis. He performed the statistical review and helped in the making of paper. Rimarcs Gomes ferreira has reviewed all the material anatomopatologico and helped in the diagnosis of HP.

(c) Article author(s) (or their employer(s) unless otherwise stated in the text of the article) 2018. All rights reserved. No commercial use is permitted unless otherwise expressly granted.

\section{Check for updates}

To cite Gimenez A, Storrer K, Kuranishi L, et al. Thorax 2018;73:391-392

Received 23 January 2017

Revised 3 July 2017

Accepted 14 July 2017

Published Online First 7 September 2017

Thorax 2018;73:391-392.

doi:10.1136/thoraxjnl-2017-210035

\section{REFERENCES}

1 Pereira CA, Gimenez A, Kuranishi L, et al. Chronic hypersensitivity pneumonitis. J Asthma Allergy 2016:9:171-81.

2 Vourlekis IS, Schwarz MI, Cherniack RM, et al. The effect of pulmonary fibrosis on survival in patients with hypersensitivity pneumonitis. Am J Med 2004;116:662-8.

3 Hanak V, Golbin JM, Hartman TE, et al. High-resolution CT findings of parenchymal fibrosis correlate with prognosis in hypersensitivity pneumonitis. Chest 2008;134:133-8

4 Ryerson CJ, Vittinghoff E, Ley B, et al. Predicting survival across chronic interstitial lung disease: the ILD-GAP model. Chest 2014:145:723-8.

5 Takemura T), Akashi T, Kamiya H, Ikushima S, Ando T, Oritsu M, Sawahata M, Ogura T. pathological differentiation of chronic hypersensitivity pneumonitis from idiopathic pulmonary fibrosis/usual interstitial pneumonia. Histopathology 2012;61:1026-35.

6 Walsh SL, Sverzellati N, Devaraj A, et al. Chronic hypersensitivity pneumonitis: high resolution computed tomography patterns and pulmonary function indices as prognostic determinants. Eur Radiol 2012;22:1672-9.

7 Reichmann WM, Yu YF, Macaulay D, et al. Change in forced vital capacity and associated subsequent outcomes in patients with newly diagnosed idiopathic pulmonary fibrosis. BMC Pulm Med 2015;15:167.

8 Karimi-Shah BA, Chowdhury BA. Forced vital capacity in idiopathic pulmonary fibrosis--FDA review of pirfenidone and nintedanib. N Engl J Med 2015:372:1189-91.

9 Pereira CA, Sato T, Rodrigues SC. New reference values for forced spirometry in white adults in Brazil. J Bras Pneumol 2007;33:397-406.

10 Morisset J, Johannson KA, Vittinghoff E, et al. Use of Mycophenolate Mofetil or Azathioprine for the management of chronic hypersensitivity pneumonitis. Chest 2017;151:619-25. 